\title{
Discontinuation Pattern Among Intrauterine Contraceptive Device Users at Jos University Teaching Hospital, Jos, Nigeria
}

\author{
Anyaka Charles, Ocheke Amaka, Shambe Iornum, Kahansim Makshwar, Oyebode Tinuade, \\ Pam Victor, Ekwempu Chinedu
}

Department of Obstetrics and Gynaecology, University of Jos/Jos University Teaching Hospital, Jos, Nigeria

Email address:

charlesanyaka@yahoo.com (Anyaka C.)

\section{To cite this article:}

Anyaka Charles, Ocheke Amaka, Shambe Iornum, Kahansim Makshwar, Oyebode Tinuade, Pam Victor, Ekwempu Chinedu. Discontinuation Pattern Among Intrauterine Contraceptive Device Users at Jos University Teaching Hospital, Jos, Nigeria. Journal of Gynecology and Obstetrics. Vol. 4, No. 6, 2016, pp. 53-56. doi: 10.11648/j.jgo.20160406.14

Received: May 13, 2016; Accepted: June 22, 2016; Published: January 3, 2017

\begin{abstract}
Context: Despite the high uptake of the intrauterine contraceptive device (IUCD), among family planning clients at Jos University Teaching Hospital (JUTH), some users discontinued its use for a variety of reasons. Objectives: To determine the discontinuation rate and factors responsible among IUCD users in the hospital over a 3 year period. Study Design: This was a 3 year retrospective descriptive study of all clients requesting for the removal of intrauterine devices (IUCDs) at the Family Planning clinic Jos University Teaching Hospital, Jos Nigeria. The study period was between January $1^{\text {st }} 2005$ and December $31^{\text {st }}$ 2007. Results: A total of 849 clients were seen during the study period; 393 (46.3\%) clients discontinued within 3 years with the highest rate at 1 year $24.2 \%$. All the women were married with $0.8 \%$ of the clients been nullipara. The most common reasons for discontinuation were the desire for pregnancy $(50.9 \%)$, excessive menstrual bleeding $(10.4 \%)$, vaginal discharge PID (9.0\%) and others. The mean age of the clients was $33.6 \pm 5.2$ years. Conclusion: The discontinuation rate of IUCD in the family planning clinic at Jos University Teaching Hospital is high. More effective counseling may be appropriate for alternative contraceptive methods for this category of clients instead of the IUCD's currently being used. The findings suggest a need for training the care providers to prevent early discontinuation of IUCD among JUTH clients and by addressing the health challenges via proper counseling, effective follow-up and prompt referral in case of complications.
\end{abstract}

Keywords: Contraceptives, IUCD, Discontinuation, Jos Nigeria

\section{Introduction}

The Intrauterine Contraceptive Device (IUCD) is a flexible frame that fits inside the uterus to prevent pregnancy and its use is getting popular with up to 100 million women worldwide using it [1]. These devices (IUCDs) have been used throughout the world for more than three decades and millions of women have found them to be effective, safe and convenient [1-3].

The intrauterine device (IUCD) provides very effective, safe and long term yet quickly reversible protection from pregnancy [4-7]. IUCDs can be one of the most cost effective contraceptive methods because modern IUCDs can be used for many years, up to 12 years $[2,4,5]$.

The desire for pregnancy, excessive menstrual bleeding and medical indications are among the leading reasons for discontinuation of the method amongst its users [8-15]. They are also removed at other times when the client makes such a request $[1,2,7]$.

The high discontinuation rate is due to challenges related to knowledge and skills of the care giver leading to improper selection of clients, deficient counseling and lack of effective follow-up. These aforementioned factors all contribute to increase the discontinuation of such an easy, affordable, and effective method of contraception. The discontinuation rate can be effectively decreased by getting recent information made available to the care provider, proper selection of cases and counseling of the patients prior to and after insertion of the devise regarding the potential side effects.

There is a paucity of reports on this subject in our environment, hence a need to find out if the experience in 
JUTH is similar to previous studies and reports. We therefore sought to determine the discontinuation pattern among IUCD users attending the family planning clinic in JUTH and to determine the factors responsible for the discontinuation.

\section{Materials and Methods}

This was a retrospective descriptive study of all clients requesting for the removal of intrauterine devices (IUCDs) at the Family Planning clinic of Jos University Teaching Hospital, Jos Nigeria. The study period was between January $1^{\text {st }} 2005$ and December $31^{\text {st }} 2007$.

Clients who were desirous to have IUCD inserted were all counselled by family planning physicians and nurses for an informed decision to be made. A detailed history, physical examination and investigations are done and an informed consent for IUCD obtained and the devise is subsequently inserted. All clients were counselled to report to the clinic if they experience any complication which usually are documented.

The records of all clients that requested for their IUCD to be removed in the family planning clinic were retrieved and relevant information extracted for analysis. The data were collated and analysed with Epi-info 8.0 statistical software packages and the results presented using simple percentages.

\section{Results}

A total of 393 intrauterine devices (IUCDs) were removed during the period of study. All the women were married. The TCu-380A was used in all the cases.

Table 1. Maternal characteristics.

\begin{tabular}{|c|c|c|}
\hline Variable & Number of clients & Percentage \\
\hline \multicolumn{3}{|l|}{ Age } \\
\hline$\leq 19$ & 2 & 0.5 \\
\hline $20-24$ & 34 & 8.7 \\
\hline $25-29$ & 105 & 26.7 \\
\hline $30-34$ & 103 & 26.2 \\
\hline $35-39$ & 76 & 19.3 \\
\hline $40-44$ & 35 & 8.9 \\
\hline $45-49$ & 28 & 7.2 \\
\hline$\geq 50$ & 10 & 2.5 \\
\hline Total & 393 & 100 \\
\hline \multicolumn{3}{|l|}{ Parity } \\
\hline 0 & 3 & 0.8 \\
\hline 1 & 68 & 17.3 \\
\hline 2 & 66 & 16.8 \\
\hline 3 & 82 & 20.8 \\
\hline 4 & 53 & 13.5 \\
\hline$\geq 5$ & 121 & 30.8 \\
\hline Total & 393 & 100 \\
\hline \multicolumn{3}{|c|}{ Number of living children } \\
\hline 0 & 3 & 0.8 \\
\hline 1 & 72 & 18.3 \\
\hline 2 & 68 & 17.3 \\
\hline 3 & 84 & 21.4 \\
\hline 4 & 58 & 14.7 \\
\hline$\geq 5$ & 108 & 27.5 \\
\hline Total & 393 & 100 \\
\hline
\end{tabular}

Table 2 shows distribution of the indications for removal of IUCD. The commonest indication was the desire for pregnancy in $50.9 \%$, excessive menstrual bleeding in $10.3 \%$, vaginal discharge/PID in $9.0 \%$. Back pain was the reason in $7.4 \%$ and partial expulsion of IUCD in $6 \%$ of the women.

Table 2 Indications for the removal of IUCD.

\begin{tabular}{llll}
\hline Indication & Number & Percentage & $\begin{array}{l}\text { Mean duration } \\
\text { of use (months) }\end{array}$ \\
\hline Desire for pregnancy & 202 & 50.9 & $18.05 \pm 14.5$ \\
Excessive menstrual bleeding & 41 & 10.4 & $11.05 \pm 10.6$ \\
Vaginal discharge/ PID & 36 & 9.0 & $17.2 \pm 16.4$ \\
Back pain & 29 & 7.4 & $32.3 \pm 40.3$ \\
Partial expulsion of IUD & 24 & 6.0 & $17.45 \pm 22.65$ \\
Wants a change of method & 14 & 6.0 & $23.4 \pm 19.75$ \\
Husband's & 18 & 4.5 & $7.15 \pm 11.3$ \\
rejection/disapproval & 16 & 4.0 & $29.0 \pm 27.35$ \\
Reached menopause & 7 & 1.8 & $16.7 \pm 16.45$ \\
Husbands death & 393 & 100 & \\
\hline
\end{tabular}

Table 3 shows removal of IUCD with progression of year. By the end of the $1^{\text {st }}$ year, $24.2 \%$ of women had the IUCD removed, $33.25 \%$ had removed by 2 years and $46.3 \%$ had removed by the $3^{\text {rd }}$ year. The mean duration of the use of IUCD in the clients was $25.7 \pm 25$ months or 2.1 years.

Table 3. Removal of IUCD with progression of year.

\begin{tabular}{lll}
\hline End of & Number of clients & Percentage \\
\hline $1^{\text {st }}$ year & 205 & 24.2 \\
$2^{\text {nd }}$ year & 289 & 33.25 \\
$3^{\text {rd }}$ year & 393 & 46.3 \\
\hline
\end{tabular}

\section{Discussion}

Women within reproductive age (20-39 years) constituted the majority $(81.5 \%)$ of clients discontinuing the method in this study. The mean age of clients in this study $33.6 \pm 5.2$ years is also similar to an earlier finding in Jos [8] of $32.9 \pm$ 6.9 years.

This is similar to earlier findings in Jos [8] and Ibadan [9] with $83.5 \%$ and $92.5 \%$ respectively of clients discontinuing IUCD who were within the reproductive age group. This finding correlates with an earlier study in Ibadan [9] which showed nearly $60 \%$ discontinuation in the younger age group.

The discontinuation at ages $>40$ years as seen in this study was comparatively low. A young woman is likely to discontinue IUCD contraceptive because she would be desirous to have more children and because of the side-effects of the device, an older woman on the other hand will be more likely to discontinue using the devise because of menopause $[16,17]$. The continued observed high popularity of IUCD use among family planning clients in reproductive age which has increased steadily in the world with subsequent discontinuation among some clients [2, 9, 12, 15], proffers an explanation to this. It also meets the needs of many women who want to end childbearing altogether and those who want to postpone child bearing for some years [18-21]. 
The commonest indication for IUD removal was the desire for pregnancy in $50.9 \%$ of clients. This is the leading indication reported by other authors in Jos [8], Ibadan [9], Irbid Jordan [13] and Kuwait [20]. This is because the intrauterine device is a contraceptive method largely used as an effective, safe, reversible and it is an economic method of contraception $[1,7]$. In numerous cohort studies 72 to $96 \%$ of women conceived within a year after their IUCD were removed [21].

From this study, $69.2 \%$ of women who discontinued IUD were of parity 4 and below, which is similar to $61.1 \%$ reported in an earlier finding in Jos [8]. Discontinuation of IUCD was also noted to be influenced by the number of living children in this study with $72.5 \%$ of clients who discontinued having 4 or fewer children. This finding is in keeping with the observed reports that the fewer a woman's children are at the time of IUCD insertion, the more likely she is to discontinue it $[12,13,17]$. Therefore women of low parity in particular need extensive motivation to continue contraceptive for a longer period of time for effective demographic impact.

Also this study showed that $0.8 \%$ of clients discontinuing IUCD were nulliparous with the desire for pregnancy been the reason for this. This is at variance with the earlier finding from Jos [8] where all the clients who discontinued IUCD had at least one living child. This contraceptive is acceptable to women who did not have children, and surveyed family planning providers around the world have reported some misbeliefs among their clients including the use of IUCD only by older women or women who have had children [2226]. This was not seen in this study.

Discontinuation of IUCD due to excessive menstrual loss accounted for $10.3 \%$ in this study. This is in agreement with other authors [11, 19, 27-29] where among women using TCu-380A IUCD the rate of termination due to bleeding was higher than the rate of termination due to other reasons, excluding the desire to conceive. This may be due to the fact that copper bearing IUCDs increase menstrual bleeding by 20-50\% above levels before IUCD insertion [21].

Discontinuation due to vaginal discharge /PID from this study was $9.0 \%$ and similar to previous reports from Jos [8] and Nairobi [2] but at variance with $0.5 \%$ reported in Leece, Italy [7]. The reported higher prevalence of IUCD discontinuation due to PID in developing countries [1] gives a possible explanation to this.

From this study $24.2 \%$ of women had discontinued IUCD by the end of the $1^{\text {st }}$ year. This is similar to findings in Jos [8] (25.6\%), Nairobi [2] (20\%), Tabriz Iran [19] (21.7\%), but with reduced rates from findings in Ibadan [9] (10.1\%), Ilorin [15] $(14.45 \%)$, Lima [ $14^{]}(14.8 \%)$, while by the end of the $3^{\text {rd }}$ year, $46.3 \%$ of clients had discontinued the method in this study which is similar to the findings in Tabriz Iran [19] $(42.4 \%)$ and Kuwait [20] (40\%). These findings underscore the revelation that the discontinuation rate for the IUCD is high in spite of the high initial acceptability of the method in Nigeria and globally [9].

The retrospective nature of the study, the single centre and relatively small sample size are some limitations of the study.

Incomplete and inadequate information available is some client's records were some of the other short comings of this study. A prospective study in collaboration with other family planning centres will improve sample size and a more robust data.

\section{Conclusion}

The findings from this study indicate a high discontinuation rate of IUCD amongst all clients cutting across all age category. The reasons for discontinuation in this study- desire for pregnancy, excessive menstrual bleeding, vaginal discharge/PID and others are similar to reports elsewhere.

Shorter lasting IUCDs may need to be revisited if these will cost less for clients wishing to use the method only to postpone pregnancies.

Family planning educators and health care providers should give more emphasis to counseling programs for women desiring IUCD insertion and during follow up. Counseling IUD users about the potential side effects and their tendency for spontaneous resolution, careful screening of candidates to ensure that women who choose IUCDs have a lower risk of side effects and complications, and the competency-based training and appropriate infectionprevention procedures are needed

In Nigeria where the prevalence of contraceptive use is low with high unmet need for family planning, it is pertinent for policy makers to improve their efforts at ensuring an appreciable continuation rate of contraceptive use in general and IUCD in particular among Nigerian women.

\section{References}

[1] Salem R. M. Richey C. IUD-An Update. Population Report. Series B No 7 Baltimore, Johns Hopkins school of Public Health, Population Information Program. Feb 2006: 3-27.

[2] Sekadde - Kigondu C, Mwathe E. E. Ruminjo JK, Nichols, D Jessencky K, Liku J. Acceptability and discontinuation of Depo-Prover, IUCD and combined pills in Kenya. East Afr Med J 199673 (12): 786-794.

[3] Oddens B. J. Women's satisfaction with birth control. A population survey of physical and psychological effects of oral contraceptives, intrauterine devices, condoms, natural family planning and sterilization among 1466 women. Contraception. 1999; 59 (5): 277-286.

[4] Aisien A. O Intrauterine contraceptive device (IUCD), acceptability and effectiveness in a tertiary institution. Afr $\mathrm{J}$ Med Sci 2007 Sep; 36 (3): 193-200.

[5] Cea Soriano L, Wallade MA, Andersson S, Filonenko A, Garcia Rodriguez L. A The continuation rates of long acting reversible contraceptives in UK general practice using data from The Health improvement Network. Pharmacoepidemiol. Drug saf 2014 sept 24. doi: 10.1002/pds.3710

[6] Gary K. S Intrauterine device. In Contraceptive technology. $17^{\text {th }}$ Edition. Ardent media Inc. 1998: 511-541. 
[7] Tinelli A, Tinelli R, Malvasi A, Cavalloti C, Tinelli F. G The intrauterine device in modern contraceptive. Still an actuality. Eur J Contracept Reprod Health Care. 2006; 11 (3): 197-201.

[8] Mutihir J. T, Ujah I. A. O, Iranloye T, Uduagbamen P. F. K. Indications for removal of intrauterine devices in Jos North Central Nigeria Niger J Clin Pract 2005; 9 (2): 105-108.

[9] Okunlola M. A, Owonikoko K. M, Robert O. A. MorhasonBello T. P Discontinuation pattern among IUCD users at the family planning clinic University College Hopsital, Ibadan. J Obstet Gynaecol. 2006; 26 (2) 152-6.

[10] Colli. E, Tong. D, Pentallegon. R, Parazzini. F. Reasons for contraceptive discontinuation in women 20-39 years old in New Zealand. Contraception 1999; 59 (4): 227-31.

[11] Tripathi V, Nandan D, Salhan S. Determinants of early discontinuation of IUCD use in rural northern district of India: a multivariate analysis and its validation. J Biosoc Sci 2005; 37 (3): 319-32.

[12] Tugrul S, Yavuzer B. Yildirim G, Kayahan A. The duration of use, cause of discontinuation and problems during removal in women admitted for removal of IUD. Contraception. 2005; 71 (2): 149-52.

[13] Khader Y. S, El-Qaderi S, Khader A. M. Intrauterine contraceptive device discontinuation among Jordanian women: rate, causes and determinants. J fam Plann Reprod Health Care; 2006; 32 (3): 161-4.

[14] Escudero F, Gonzales G F, Delgadillo L, Villena A. E. Factors associated with discontinuation rates of the copper T 380A IUD in a Peruvian public hospital. Adv contracept 1999; 15 (4): 303-11.

[15] Jimoh A. A. Complications of intrauterine contraceptive device (IUD) use at the University of Ilorin Teaching Hospital, Ilorin. Niger J Med. 2004; 13 (3) 244-9.

[16] Badaruddin A, Shallwani S, Hussain F A, Sultana M, Parveen F. Social and personal factors affecting continuation of contraceptive use. 1998, Available at: http/www.mopw.gov.pk/nrifc/socialpers

[17] Ali M, Cleland J. Contraceptive discontinuation in six developing countries. A cause-specific analysis. International Family Planning 1995; 21: 92-97.

[18] Marret H, Golfier F, Vollerin F, Legoaziou M. F. Raudrant D. Intrauterine devices in general practice: a prospective study of 300 insertions. J Gynecol obstet Biol Reprod Paris. 2002; 31 (5): $465-70$
[19] Jenabi E, Alizade S. M, Baga RI. Continuation rates and reasons for discontinuing TCu380A IUD use in Tabriz, Iran. Contraception. 2006; 74 (6): 483-6.

[20] Shah N. M, Shah M. A, Chowdhury R. I, Menon I. Reasons and correlates of contraceptive discontinuation in Kuwait. Eur J Contraceptive Reprod Health Care: 2007; 12 (3) 260-8.

[21] Treiman K, Liskin L, Kols A, Rinehart W. IUDs-An update. Population Report. Series B, No 6 Baltmore, Johns Hopkins school of Public Health, Population information program. Dec 1995: 35 .

[22] Farr. G, Amatya R, Acosta M, Ekwempu CC, Kisninci H. Clinical performance of the TCu 380A and Lippes loop IUDs in three developing countries. Contraception. 1995; 52 (1): 1722.

[23] Reinprayon D. Gilmore C, Farr G, Amatya R. Twelve-month comparative multicentre study of the TCu 380A and ML 250 intrauterine devices in Bangkok, Thailand. Contraception. 1998; 58 (4): 201-206.

[24] WHO, Department of Reproductive Health and Research and UNDP/UNFPA/WHO/World bank special programme of research, development and research training in human reproduction. Annual technical report 2003. Geneva, WHO 2003.

[25] Pakarinen P. I, Toivonen J, Luukkainen T. Randomised comparison of levonorgestrel and copper-releasing intra uterine systems immediately after abortion with 5 years follow-up. Contraception 2003; 68 (1) 31-34.

[26] $\mathrm{Wu} \mathrm{S}, \mathrm{Hu}$ J, Wildemeersch D. Performance of the frameless gynefix and the TCu 380A IUDs in a 3 year multicentre randomized, comparative trial in parous women. Contraception. 2000; 61 (2): 91-98.

[27] International planned parenthood federation (IPPF) and World Health Organisation (WHO). The intrauterine device (IUD) (Draft). IPPF and WHO. IPPF/WHO myth monograph. 2001: 21.

[28] Toma A, Jamieson MA,. Revisiting the intra uterine contraceptive device in adolescents. J Pediatr Adolesc Gynaecol 2006; 19 (4): 291-6.

[29] Dimkpa O. J, Okwudili O. E, Wamadi N. E Intrauterine Contraceptive Device Use in Port Harcourt, Southern Nigeria: A Retrospective Analysis. British Journal of Medicine \& Medical Research 2014; 4 (16): 3132-3139. 